\title{
Pax4 and Arx Represent Crucial Regulators of the Development of the Endocrine Pancreas
}

\author{
Monica Courtney, ${ }^{1,2,3}$ Tamara Rabe, ${ }^{3,4}$ Patrick Collombat, ${ }^{1,2,3,5}$ and Ahmed Mansouri ${ }^{3,4,5,6}$ \\ ${ }^{1}$ Université de Nice-Sophia Antipolis, Laboratoire de Génétique du Développement Normal et Pathologique, 06108 Nice, France \\ ${ }^{2}$ Inserm U1091, IBV, Diabetes Genetics Team, 06108 Nice, France \\ ${ }^{3}$ JDRF, 26 Broadway, NY 10004, USA \\ ${ }^{4}$ Department of Molecular Cell Biology, Max-Planck Institute for Biophysical Chemsitry, Am Fassberg 11, 37077 Goettingen, Germany \\ ${ }^{5}$ Genome and Stem Cell Center, GENKOK, Erciyes University, Kayseri, Turkey \\ ${ }^{6}$ Department of Clinical Neurophysiology, University of Goettingen, Robert-Koch-Straße 40, 37075 Goettingen, Germany
}

Correspondence should be addressed to Patrick Collombat; collombat@unice.fr and Ahmed Mansouri; amansou@gwdg.de

Received 10 April 2014; Accepted 12 May 2014; Published 29 May 2014

Academic Editor: Hui-Qi Qu

Copyright (C) 2014 Monica Courtney et al. This is an open access article distributed under the Creative Commons Attribution License, which permits unrestricted use, distribution, and reproduction in any medium, provided the original work is properly cited.

The development of the endocrine pancreas is under the control of highly orchestrated, cross-interacting transcription factors. Pancreas genesis is initiated by the emergence of a Pdx1/Ptfla marked territory at the foregut/midgut junction. A small fraction of pancreatic fated cells activates the expression of the bHLH transcription factor Ngn3 triggering the endocrine cell program, thus giving rise to beta-, alpha-, delta-, $\mathrm{PP}-$, and epsilon-cells, producing insulin, glucagon, somatostatin, pancreatic polypeptide, and ghrelin, respectively. Two transcription factors, Pax4 and Arx, play a crucial role in differential endocrine cell subtype specification. They were shown to be necessary and sufficient to endow endocrine progenitors with either a beta- or alpha-cell destiny. Interestingly, whereas the forced expression of Arx in beta-cells-converts these into cells exhibiting alpha- and PP-cell characteristics, the sole expression of Pax4 in alpha-cells promotes alpha-cell neogenesis and the acquisition of beta-cell features, the resulting beta-like cells being capable of counteracting chemically induced diabetes. Gaining new insights into the molecular mechanisms controlling Pax4 and Arx expression in the endocrine pancreas may therefore pave new avenues for the therapy of diabetes.

\section{Introduction}

The pancreas is composed of two distinct functional cell compartments. The major part comprises the exocrine tissue consisting of acinar cells secreting digestive enzymes and an intricate ductal system required for the transport of the digestive juice to the duodenum. The endocrine compartment is found scattered throughout the exocrine tissue and is organized into aggregates of hormone-producing cells forming functional units called islets of Langerhans $[1,2]$. The mouse insulin-producing beta-cells are located in the core of the islets, whereas the remaining cells, expressing the hormones glucagon (alpha-cells), somatostatin (delta-cells), pancreatic polypeptide (PP-cells), and ghrelin (epsilon-cells), are detected in islet periphery $[1,3]$.
Insulin producing beta-cells are required to maintain glucose homeostasis. Indeed, their loss or malfunction eventually results in diabetes. Although medication aiming at controlling glycemia has improved, glycemic control is often difficult to achieve leading to side effects such as hypoglycemic episodes. Therefore, it is of fundamental interest to develop alternative therapeutic approaches, such as stem cell replacement, aiming at replenishing the beta-cell mass. Towards this goal, understanding the molecular mechanisms controlling beta-cell genesis represents a key step.

During embryonic development, pancreas formation is characterized by the appearance of a ventral and a dorsal bud at the foregut/midgut junction. The pancreatic cell territory is labeled by the expression of two transcription factors, Pdxl and Ptfla. Lineage tracing studies revealed that 
Pdx1- and Ptfla-expressing cells contribute to the development of all pancreatic derivatives [1,3-6]. Subsequently, the pancreatic epithelium proliferates and only a minor cell population becomes fated to the endocrine compartment, such cells being characterized by the expression of the transcription factor Ngn3. Ngn3 is necessary for the formation of endocrine hormone-expressing cells as its absence results in the loss of islet cell genesis $[7,8]$. At E12.5, the dorsal and ventral pancreatic primordia fuse and at around E13.5, during the so-called secondary transition [2], pancreatic multipotent progenitor cells, which are marked by the expression of Pdxl, Ptfla, Cpal, and c-myc, are detected in the tip of the branching epithelium [9]. At early stages of development these multipotent progenitors have the propensity to give rise to Ngn3+ progenitor, acinar, and ductal cell lineages. However, after E14, Cpal-positive cells lose their multipotency and are able to generate only exocrine cells [9]. Endocrine precursors initiate the expression of various transcription factors and differentiate to give rise to pancreatic hormoneproducing cells. Among these transcription factors, Pax 4 and Arx were shown to play a central role in the allocation of endocrine progenitors towards the insulin producing betacell and glucagon producing alpha-cell fates, respectively $[1$, $10,11]$. Herein, we will discuss in detail our studies concerning the function of Pax4 and Arx in endocrine cell subtype specification and their possible future implication in the development of therapeutic approaches aiming at treating diabetes.

\section{Expression of Pax4 and Arx during Pancreas Development}

Pax4 is a member of the paired-box containing family of transcription factors [12]. Together with Pax6, it plays a crucial role in endocrine pancreas morphogenesis $[13,14]$. During pancreas development, Pax4 is first detected in the pancreatic epithelium at E9.5 [15]. At later stages and in adults, Pax4 expression is restricted to beta-cells [15]. Interestingly, a study using the Pax4 promoter to drive Notch expression in the endocrine pancreas in combination with lineage tracing revealed that Pax4-expressing cells may represent specified endocrine progenitors, contributing equally to all four islet subtypes [16]. Several immunohistochemical studies clearly confirm that Pax4 is also found in mature beta-cells $[17,18]$.

The Aristaless-related homeobox-encoding gene Arx is expressed in the central nervous system, in skeletal muscles, and in the endocrine pancreas $[11,19,20]$. It is first detected at E9.5 in the pancreatic epithelium and was found to mark beta- and alpha-precursor cells prior to becoming confined to alpha- and PP-cells in adults [11]. During pancreas genesis, we have previously shown that Pax4 and Arx are present in the same proendocrine cell [11]. The molecular mechanisms leading to the segregation of Arx- and Pax4-expressing cells are not known. However, recent findings have demonstrated that in committed beta-cells, the repression of Arx is achieved through methylation of the Arx locus [21]. Accordingly, in the absence of Dnmt1 gene activity, Arx expression is reactivated in beta-cells converting them into alpha-cells. Another study further sustains these findings showing that the targeted inactivation of Dnmt3a in beta-cells is able to convert these into alpha-cells in an Arx-dependent manner [22]. Moreover, it has been suggested that the repression of Arx gene activity, required to maintain the beta-cell fate, could be achieved through Nkx2.2 interaction with the methylated Arx promoter [22]. Along the same lines, we have demonstrated that beta-cell commitment is mediated by cross-inhibitory interactions between Arx and $\operatorname{Pax} 4([1,10,11]$, and see below).

\section{The Role of Pax4 and Arx in Endocrine Cell Subtype Specification}

The transcription factor, Ngn3, which is expressed in all endocrine progenitors, is necessary for the formation of the endocrine pancreas $[7,8]$. Subsequently, a concerted action of various transcription factors is required for the specification, differentiation, and survival of the different hormone-producing endocrine cell types. We have focused our studies on the role of Pax 4 and Arx in these processes. The expression pattern of Pax 4 and Arx during pancreas genesis already indicated that these two factors might promote the specification of endocrine cells. The analysis of Pax4 and Arx loss- and gain-of-function mutant mice sustained this notion. Indeed, in the absence of Pax 4 function, mutant mice suffer from hyperglycemia and die 2 days postpartum. Mutant islets are morphologically normal, but the core insulinproducing cells are lost. Instead, beta-cells appear to be replaced by a proportional increase in glucagon-labeled cells. In addition, somatostatin-expressing cells are missing [15]. This finding suggested that Pax4 not only is required for the specification of beta- and delta-cells, but also may repress the alpha-cell lineage [15]. Hence, in the absence of Pax4, endocrine progenitors are shunted towards an alpha-cell fate at the expense of a beta-/delta-cell destiny. Arx mutant mice die two days postpartum and suffer from hypoglycemia [11]. Interestingly, in these mutant animals, a phenotype opposite to that observed in Pax4-deficient animals is noted. Indeed, we found that, in mutant Arx pancreata, alpha-cells are depleted, whereas the beta- and delta-cell contents are proportionally increased. Besides, in Arx-deficient pancreata, Pax4 transcription appeared upregulated, clearly providing evidence of a cross-regulation between the expression of Arx and Pax4 in pancreatic endocrine cell fate specification ([1, 11], and see below). We concluded that, in the absence of Arx activity, endocrine progenitor cells are allocated to a beta/delta-cell destiny, whereas Pax4-deficiency is accompanied with a favoring of an alpha-cell fate at the expense of beta-/delta-cell lineage $[10,11]$. In addition, further studies uncovered a reciprocal cross-inhibitory interaction between Arx and Pax4. Indeed, combining Gel Mobility Shift Assay (EMSA) and Chromatin ImmunoPrecipitation (ChIP), we established that Pax4 could specifically bind to a region localized at the $3^{\prime}$ end of the Arx gene and efficiently repress its transcription. Similar experiments using E14 pancreas indicated an interaction of Arx with a 200-bp DNA fragment present within the Pax4 enhancer. It appears therefore that Arx and Pax4 directly interact with the respective promoter and repress each other's transcription [10]. 


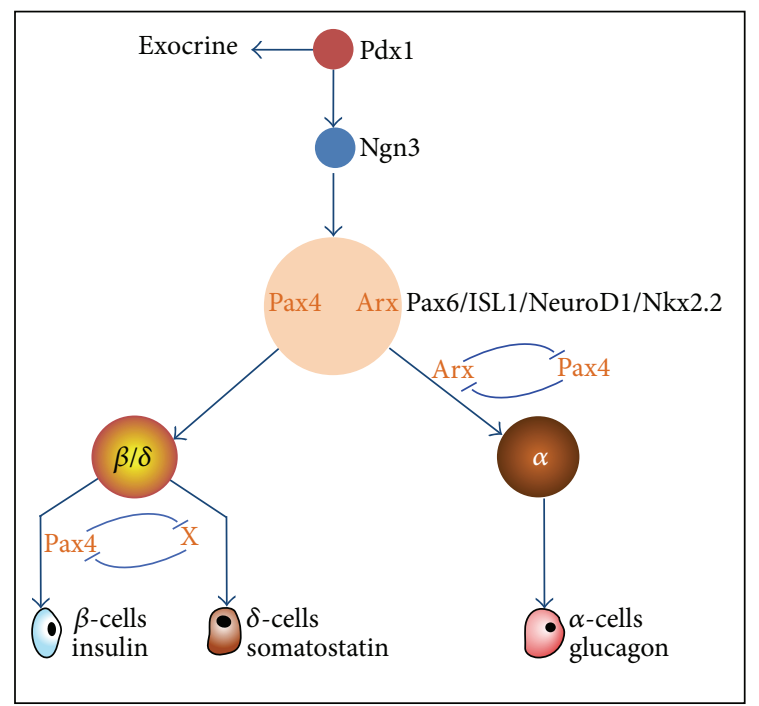

FIgURE 1: Cross-inhibitory interaction between Pax4 and Arx promotes endocrine cell subtype allocation. Pancreatic progenitors expressing the transcription factor Pdxl become fated to endocrine and exocrine compartments. The endocrine cell program is initiated by the activation of the b-HLH transcription factor Ngn3. Endocrine progenitors are allocated in a first round of cross-inhibitory interactions between Pax 4 and Arx to a beta-/delta-cell fate or an alphacell destiny, respectively. Similarly, a second round of repressive interaction between Pax 4 and an unknown factor X will promote the differentiation into beta- and delta-cells, respectively.

Immunohistochemical analysis revealed that pancreata derived from Pax4/Arx double mutant animals display an increased number of somatostatin-expressing delta-cells, while alpha- and beta-cells are missing. This unexpected finding revealed a secondary role for Pax 4 in beta-cell genesis. Accordingly, our data demonstrate that Pax4 first promotes endocrine precursors towards a beta-/delta-cell fate and subsequently towards a beta-cell lineage. These data are consistent with a model where an additional factor (X) inducing the delta-cell fate is necessary to repress Pax4 activity, possibly through an analogous reciprocal interaction mechanism, as shown for Pax4 and Arx [10] (Figure 1). Future genomic analysis may reveal the identity of such a factor.

Another transcription factor involved in beta-cell differentiation is $\mathrm{Nkx2.2}$. Indeed, the loss of $N k \times 2.2$ gene activity provokes the appearance of immature beta-cells in mutant pancreata [23]. Of note is the observed upregulation of Arx transcription in the pancreas of these mutant animals, suggesting a possible interaction between these two factors [24-26]. We have generated Arx/Nkx2.2 compound mutant mice. The analysis of double mutant pancreata revealed that Nkx2.2 might act to sustain the transcriptional network in which Pax4 and Arx are involved to endow endocrine precursors with beta- and alpha-cell destinies, respectively [25]. This finding is consistent with the notion that the concerted action of Pax 4 and Nkx2.2 is required to antagonize Arx activity in differentiating beta-cells $[25,26]$.

Thus, our results clearly establish Pax4 and Arx as major players acting in the allocation to the different endocrine

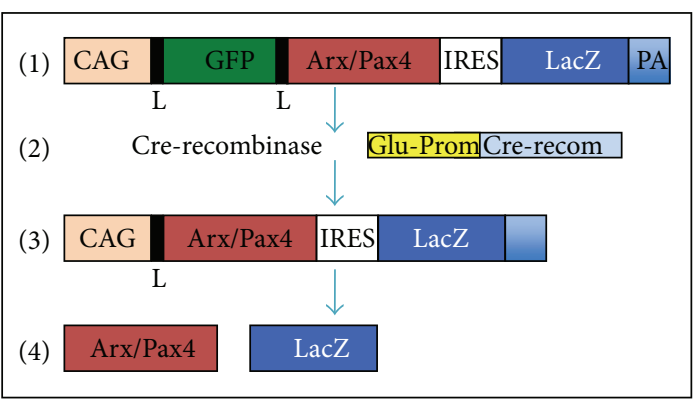

FIgUre 2: Pax4 and Arx are necessary and sufficient to promote the beta- and alpha-cell fate/identity, respectively. Schematic describing the strategy used to conditionally force the expression of Pax 4 or Arx in the pancreatic endoderm, in endocrine cells or in alpha- or beta cells, depending on the promoter used to drive the expression of the Cre recombinase. (1) Transgenic mice carrying a construct allowing the conditional activation of Pax4 or Arx expression under the control of beta-actin/CMV (promoter/Enhancer) display ubiquitous green fluorescent protein (GFP) expression. LoxP (L) sites (black bars) flanking GFP coding sequences and a stop codon allowing the activation of Pax4 or Arx only following the crossing of these mice with transgenic mice expressing the Cre recombinase under the control of pancreatic promoters (2) (Table 1). Double transgenic mice carrying the constructs (1) and (2) will undergo Cre-induced homologous recombination to express Pax 4 or Arx in conjunction with the marker LacZ ((3) and (4)), allowing the tracing of Pax4-expressing cells.

TABLE 1

\begin{tabular}{ll}
\hline Pdx1-promoter & Expression in pancreatic endoderm \\
Pax6-promoter & Expression in all endocrine cells \\
Pdx1-CreERT2 & Inducible by tamoxifen in beta-cells \\
Glu-Cre & Expression in alpha-cells \\
RIP-Cre & Expression in beta-cells \\
\hline
\end{tabular}

cell fates. Hence, manipulating the expression of Pax4 and Arx may pave new avenues to derive beta-cells from stem/progenitor cells to develop novel strategies for the treatment of diabetes.

\section{Pax4 and Arx As Cell Identity Determinants in the Endocrine Pancreas}

Based on the aforementioned results, we queried whether Pax 4 and Arx were not only necessary but also sufficient to drive endocrine progenitors towards a beta- and alpha-cell fate, respectively. Thus, we took advantage of the site-specific Cre recombinase system to force the expression of either Pax4 or Arx in endocrine cells, during development, and in adult animals. As shown in Figure 2, using different transgenic mouse lines (see Table 1), we were able to force the expression of Arx or Pax 4 in the pancreatic endoderm, in endocrine cells and in alpha- or in beta-cells. In addition, in the double transgenic mice, the activation of betagalactosidase expression is induced serving as marker to label and follow those cells that are forced to express Pax4 or Arx (Figure 2). 
Remarkably, the analysis of transgenic mice allowing the forced expression of Arx in Pdx1-labelled pancreatic precursors, in Pax6-expressing endocrine cells, or even in mature beta-cells (using inducible Pdxl-Cre mice), revealed a strong hyperglycemia leading to precocious death [27]. Accordingly, immunohistochemical endocrine marker analyses and quantification of islet cells clearly demonstrated that, in all transgenic mouse lines, a consistent increase in the number of cells with alpha- and PP-cell characteristics occurred. In contrast, the number of insulin-producing cells was dramatically reduced [27]. These data indicate that the sole forced expression of Arx in pancreatic cells at different developmental and adult stages is sufficient to induce changes in islet cell destiny [27]. It is interesting to note that the misexpression of Arx in mature beta-cells is able to convert these into cells displaying alpha- and PP-cell features. Thus, towards the goal of generating beta-cells from endocrine cells, we also forced the expression of the transcription factor Pax4 not only in the pancreatic endoderm but also in endocrine cells at different stages of endocrine cell development [17]. Using a similar strategy as described for Arx, the conditional misexpression of Pax4 during development revealed its role in promoting the beta-cell fate [17]. Importantly, a conversion of alpha-cells into beta-like cells was noted through the forced expression of Pax4 in alpha-cells. Indeed, transgenic mice expressing Pax4 in alpha-cells displayed an age-dependent increase of the beta-cell mass, leading to hypertrophic islets provoked by hyperplasia of insulinexpressing cells. Lineage tracing indicated that these betalike cells were converted from alpha-cells in which Pax4 was misexpressed [17]. The increase in islet size was intriguing and pointed to permanent regeneration of the alpha-cell pool. In fact, this was consistent with the idea that compromising the glucagon signaling pathway is associated with alpha-cell regeneration (Figure 3). Indeed, mice lacking the glucagon receptor, prohormone convertase 2 , or glucagon gene-derived peptides display alpha-cell hyperplasia [28-30]. Accordingly, glucagon supplementation in Pax4 misexpressing mice was able to diminish the dramatic increase in islet size [17]. Thus, in Pax4 transgenic mice, glucagon signaling alteration contributes to alpha-cell regeneration, these cells being converted into beta-like cells upon Pax4 misexpression. Of note was the replenishment of insulin producing beta-cells observed in Pax4 misexpressing mice following chemically induced diabetes. Sixty days after the initiation of betacell ablation, islets exhibited a normal content of insulinproducing cells that were derived from converted alpha-cells expressing Pax4. Altogether these results indicate that the forced expression of Pax4 in alpha-cells is able to induce their neogenesis and conversion into functional beta-like cells. These processes were found to depend on the reexpression of the proendocrine gene Ngn3 in the ductal lining, supporting the notion of the existence of precursor cells in ducts $[17,31-$ 37].

The misexpression of Pax4 in alpha-cells was achieved using transgenic mice expressing the Cre recombinase under the control of the glucagon promoter (see Figure 2). Accordingly, in such a strategy, Pax4 expression was induced in newly developed alpha-cells [17]. Therefore, it is reasonable

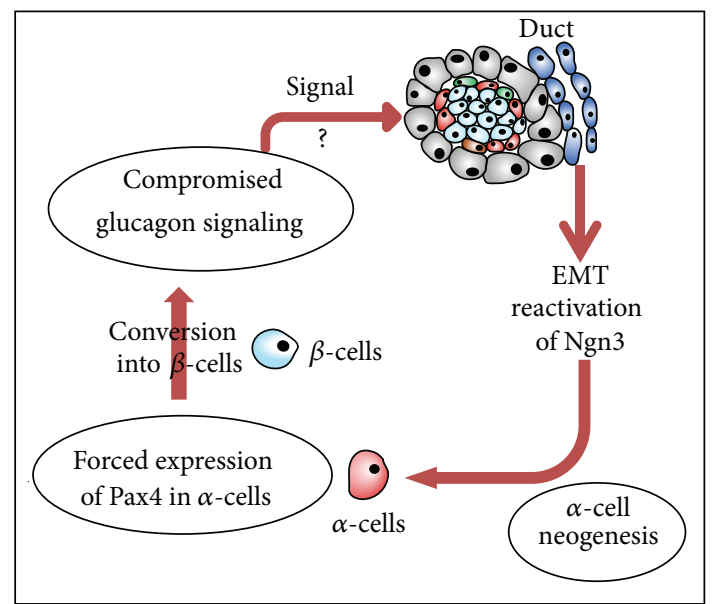

Figure 3: The forced expression of Pax4 in alpha-cells induces their conversion to beta-like cells. The use of the site-specific recombination (Figure 2) as well as the tetracycline inducible system to control the forced expression of Pax 4 in alpha-cells was found to induce their conversion into functional beta-like cells and to promote a concomitant induction of alpha-like cell regeneration. The shortage in glucagon provoked by the conversion of alphacells into beta-cells appeared to contribute to the mobilization of duct-lining precursor cells that reactivate Ngn3 and undergo EMT (epithelial mesenchymal transition) prior to adopting an alpha-like cell identity. Such cells are yet again turned into beta-like cells upon Pax4 misexpression, and should it be maintained.

to query whether glucagon-producing alpha-cells residing in the islets of adult mice and being exposed to epigenetic environment are also capable of undergoing such conversion upon Pax 4 misexpression. Hence, taking advantage of the inducible tetracycline system, Pax4 expression was activated in alpha-cells of adult mice at various ages and for different periods of time. Pax4 expression in alpha-cells was triggered and controlled for a definite time period by the supplementation of doxycycline in the drinking water [38]. Remarkably, using this system, not only could adult alphacells be converted into beta-like cells but also a continuous cycle of alpha-cell neogenesis was observed. It is interesting to note that this process was age-independent. Transgenic animals could survive several cycles of chemically-induced beta-cell ablation and regenerate multiple times their whole beta-like cell mass [38]. Lineage tracing experiments using the site-specific Cre recombinase system clearly established that: (a) newly generated beta-like cells were converted from alpha-cells and (b) a cycle of alpha-cell neogenesis was induced, such cells originating from duct-lining cells that reactivated Ngn3 expression and underwent EMT (epithelial mesenchymal transition) [38]. Indeed, in areas adjacent to ducts, mesenchymal-like structures were observed where the expression of mesenchymal markers such as nestin, vimentin, snail2, and Soxll was activated [38, 39]. Taken together, these findings indicate that the alpha-cell pool in the endocrine pancreas has the propensity to regenerate and may therefore represent a valuable source to give rise to new beta-cells [36]. Therefore, testing the ability of PAX4 
to convert human alpha-cells into functional beta-cells is of fundamental interest for the development of therapeutic approaches to treat diabetes.

As reported above, during the course of development, Pax4 and Arx undergo a reciprocal cross-inhibitory interaction allowing the differential specification towards the betaand alpha-cell fates, respectively $[1,10]$. Accordingly, the conversion of alpha-cells into beta-like cells mediated by the forced activation of Pax4 expression may also be due to the concomitantly suppressed Arx gene activity in glucagonproducing cells. It is therefore reasonable to assume that the downregulation of Arx gene function in adult glucagonproducing cells may promote their transdifferentiation into beta-cells. This has recently been demonstrated by the conditional inactivation of Arx in adult alpha-cells, which resulted in the appearance of newly generated insulin-producing betacells [40]. Moreover, this alpha-to-beta-like cell transdifferentiation induced process triggering a cycle of alpha-cell neogenesis, as has been noted in Pax4 misexpressing mice [38-40]. Remarkably, the conditional double knockout of Arx and Pax4 in adult alpha-cells still efficiently promotes the transdifferentiation of glucagon-producing cells into betalike cells that could counter chemically induced diabetes [40]. These findings are consistent with the idea that Arx functional inactivation is the main driving force in achieving the reprograming of alpha-cells into beta-cells [40]. Therefore, novel strategies allowing the downregulation of Arx expression or of its downstream targets in alpha-cells could open new avenues to develop innovative approaches for generating beta-cells to treat diabetes. The identification of Arx target genes and/or interacting factors may represent an important step in reaching this goal. In addition, future studies are also required to determine whether human alphacells are able to transdifferentiate into beta-like cells upon Pax4 forced expression or by targeting Arx inactivation. Further exploration of the molecular interactions mechanisms controlling endocrine cell subtype specification in the endocrine pancreas may also uncover novel candidate molecules that allow the establishment of strategies to directly provoke alpha- to beta-cell reprogramming in vivo.

\section{Conflict of Interests}

The authors declare that there is no conflict of interests regarding the publication of this paper.

\section{Authors' Contribution}

M. Courtney and T. Rabe contributed equally.

\section{Acknowledgments}

This work was supported by the Juvenile Diabetes Research foundation (17-2011-16, 2-2010-567, 26-2008-639, and 172013-426), the INSERM AVENIR program, the INSERM, the European Research Council (StG-2011-281265), the FMR (DRC20091217179), the ANR/BMBF (2009 GENO 105 01/01KU0906), the "Investments for the Future" LABEX SIGNALIFE (ANR-11-LABX-0028-01), the Max-Planck Society, Club Isatis, Mr. and Mrs Dorato, the Fondation Générale de
Santé, and the Foundation Schlumberger pour l'Education et la Recherche.

\section{References}

[1] P. Collombat, J. Hecksher-Sorensen, P. Serup, and A. Mansouri, "Specifying pancreatic endocrine cell fates," Mechanisms of Development, vol. 123, no. 7, pp. 501-512, 2006.

[2] R. L. Pictet, W. R. Clark, R. H. Williams, and W. J. Rutter, "An ultrastructural analysis of the developing embryonic pancreas," Developmental Biology, vol. 29, no. 4, pp. 436-467, 1972.

[3] F. C. Pan and C. Wright, "Pancreas organogenesis: from bud to plexus to gland," Developmental Dynamics, vol. 240, no. 3, pp. 530-565, 2011.

[4] G. K. Gittes, "Developmental biology of the pancreas: a comprehensive review," Developmental Biology, vol. 326, no. 1, pp. 4-35, 2009.

[5] G. Gu, J. R. Brown, and D. A. Melton, "Direct lineage tracing reveals the ontogeny of pancreatic cell fates during mouse embryogenesis," Mechanisms of Development, vol. 120, no. 1, pp. 35-43, 2003.

[6] Y. Kawaguchi, B. Cooper, M. Gannon, M. Ray, R. J. MacDonald, and C. V. E. Wright, "The role of the transcriptional regulator Ptfla in converting intestinal to pancreatic progenitors," Nature Genetics, vol. 32, no. 1, pp. 128-134, 2002.

[7] G. Gradwohl, A. Dierich, M. LeMeur, and F. Guillemot, "neurogenin 3 is required for the development of the four endocrine cell lineages of the pancreas," Proceedings of the National Academy of Sciences of the United States of America, vol. 97, no. 4, pp. 16071611, 2000.

[8] V. M. Schwitzgebel, D. W. Scheel, J. R. Conners et al., "Expression of neurogenin 3 reveals an islet cell precursor population in the pancreas," Development, vol. 127, no. 16, pp. 3533-3542, 2000.

[9] Q. Zhou, A. C. Law, J. Rajagopal, W. J. Anderson, P. A. Gray, and D. A. Melton, "A multipotent progenitor domain guides pancreatic organogenesis," Developmental Cell, vol. 13, no. 1, pp. 103-114, 2007.

[10] P. Collombat, J. Hecksher-Sorensen, V. Broccoli et al., "The simultaneous loss of Arx and Pax4 genes promotes a somatostatin-producing cell fate specification at the expense of the $\alpha$ - and $\beta$-cell lineages in the mouse endocrine pancreas," Development, vol. 132, no. 13, pp. 2969-2980, 2005.

[11] P. Collombat, A. Mansouri, J. Hecksher-Sorensen et al., "Opposing actions of Arx and Pax4 in endocrine pancreas development," Genes \& Development, vol. 17, no. 20, pp. 2591-2603, 2003.

[12] A. Mansouri, M. Hallonet, and P. Gruss, "Pax genes and their roles in cell differentiation and development," Current Opinion in Cell Biology, vol. 8, no. 6, pp. 851-857, 1996.

[13] A. Mansouri, G. Goudreau, and P. Gruss, "Pax genes and their role in organogenesis," Cancer Research, vol. 59, no. 7, pp.1707S1710S, 1999.

[14] A. Mansouri, L. St-Onge, and P. Gruss, "Role of Pax genes in endoderm-derived organs," Trends in Endocrinology \& Metabolism, vol. 10, no. 4, pp. 164-167, 1999.

[15] B. Sosa-Pineda, K. Chowdhury, M. Torres, G. Oliver, and P. Gruss, "The Pax4 gene is essential for differentiation of insulinproducing $\beta$ cells in the mammalian pancreas," Nature, vol. 386, no. 6623, pp. 399-402, 1997. 
[16] A. L. Greenwood, S. Li, K. Jones, and D. A. Melton, "Notch signaling reveals developmental plasticity of $\mathrm{Pax} 4^{+}$pancreatic endocrine progenitors and shunts them to a duct fate," Mechanisms of Development, vol. 124, no. 2, pp. 97-107, 2007.

[17] P. Collombat, X. Xu, P. Ravassard et al., “The ectopic expression of Pax4 in the mouse pancreas converts progenitor cells into $\alpha$ and subsequently $\beta$ cells," Cell, vol. 138, no. 3, pp. 449-462, 2009.

[18] J. Lu, P. L. Herrera, C. Carreira et al., " $\alpha$ cell-specific Men1 ablation triggers the transdifferentiation of glucagon-expressing cells and insulinoma development," Gastroenterology, vol. 138, no. 5, pp. 1954-1965, 2010.

[19] S. Biressi, G. Messina, P. Collombat et al., "The homeobox gene Arx is a novel positive regulator of embryonic myogenesis," Cell Death and Differentiation, vol. 15, no. 1, pp. 94-104, 2008.

[20] E. Colombo, P. Collombat, G. Colasante et al., "Inactivation of Arx, the murine ortholog of the X-linked lissencephaly with ambiguous genitalia gene, leads to severe disorganization of the ventral telencephalon with impaired neuronal migration and differentiation," The Journal of Neuroscience, vol. 27, no. 17, pp. 4786-4798, 2007.

[21] S. Dhawan, S. Georgia, S.-I. Tschen, G. Fan, and A. Bhushan, "Pancreatic $\beta$ cell identity is maintained by DNA methylationmediated repression of Arx," Developmental Cell, vol. 20, no. 4, pp. 419-429, 2011.

[22] J. B. Papizan, R. A. Singer, S.-I. Tschen et al., " $N k x 2.2$ repressor complex regulates islet $\beta$-cell specification and prevents $\beta$-to- $\alpha$ cell reprogramming," Genes \& Development, vol. 25, no. 21, pp. 2291-2305, 2011.

[23] L. Sussel, J. Kalamaras, D. J. Hartigan-O’Connor et al., "Mice lacking the homeodomain transcription factor $N k \times 2.2$ have diabetes due to arrested differentiation of pancreatic $\beta$ cells," Development, vol. 125, no. 12, pp. 2213-2221, 1998.

[24] C. S. Chao, Z. L. Loomis, J. E. Lee, and L. Sussel, “Genetic identification of a novel NeuroD1 function in the early differentiation of islet $\alpha$, PP and $\varepsilon$ cells," Developmental Biology, vol. 312, no. 2, pp. 523-532, 2007.

[25] S. Kordowich, P. Collombat, A. Mansouri, and P. Serup, “Arx and $N k \times 2.2$ compound deficiency redirects pancreatic alphaand beta-cell differentiation to a somatostatin/ghrelin coexpressing cell lineage," BMC Developmental Biology, vol. 11, article 52, 2011.

[26] T. L. Mastracci, C. Wilcox, L. Arnes et al., "Nkx2.2 and Arx genetically interact to regulate pancreatic endocrine cell development and endocrine hormone expression," Developmental Biology, vol. 359, no. 1, pp. 1-11, 2011.

[27] P. Collombat, J. Hecksher-Sorensen, J. Krull et al., "Embryonic endocrine pancreas and mature $\beta$ cells acquire $\alpha$ and PP cell phenotypes upon Arx misexpression," The Journal of Clinical Investigation, vol. 117, no. 4, pp. 961-970, 2007.

[28] M. Furuta, H. Yano, A. Zhou et al., "Defective prohormone processing and altered pancreatic islet morphology in mice lacking active SPC2," Proceedings of the National Academy of Sciences of the United States of America, vol. 94, no. 13, pp. 66466651, 1997.

[29] R. W. Gelling, X. Q. Du, D. S. Dichmann et al., "Lower blood glucose, hyperglucagonemia, and pancreatic $\alpha$ cell hyperplasia in glucagon receptor knockout mice," Proceedings of the National Academy of Sciences of the United States of America, vol. 100, no. 3, pp. 1438-1443, 2003.

[30] Y. Hayashi, M. Yamamoto, H. Mizoguchi et al., "Mice deficient for glucagon gene-derived peptides display normoglycemia and hyperplasia of islet $\alpha$-cells but not of intestinal L-cells," Molecular Endocrinology, vol. 23, no. 12, pp. 1990-1999, 2009.

[31] P. Collombat and A. Mansouri, "Pax4 transdifferentiates glucagon-secreting $\alpha$ cells to insulin-secreting $\beta$ endocrine pancreatic cells," Medecine/Sciences, vol. 25, no. 8-9, pp. 763765, 2009.

[32] P. Collombat and A. Mansouri, "Turning on the $\beta$-cell identity in the pancreas," Cell Cycle, vol. 8, no. 21, pp. 3450-3451, 2009.

[33] Y. Dor and D. A. Melton, "Facultative endocrine progenitor cells in the adult pancreas," Cell, vol. 132, no. 2, pp. 183-184, 2008.

[34] J. F. Habener and V. Stanojevic, " $\alpha$-cell role in $\beta$-cell generation and regeneration," Islets, vol. 4, no. 3, pp. 188-198, 2012.

[35] Z. Liu and J. F. Habener, "Alpha cells beget beta cells," Cell, vol. 138, no. 3, pp. 424-426, 2009.

[36] A. Mansouri, "Development and regeneration in the endocrine pancreas," ISRN Endocrinology, vol. 2012, Article ID 640956, 12 pages, 2012.

[37] X. Xu, J. D’Hoker, G. Stangé et al., “ $\beta$ cells can be generated from endogenous progenitors in injured adult mouse pancreas," Cell, vol. 132, no. 2, pp. 197-207, 2008.

[38] K. Al-Hasani, A. Pfeifer, M. Courtney et al., "Adult duct-lining cells can reprogram into $\beta$-like cells able to counter repeated cycles of toxin-induced diabetes," Developmental Cell, vol. 26, no. 1, pp. 86-100, 2013.

[39] A. Pfeifer, M. Courtney, N. Ben-Othman et al. et al., "Induction of multiple cycles of pancreatic $\beta$-cell replacement," Cell Cycle, vol. 12, no. 20, pp. 3243-3244, 2013.

[40] M. Courtney, E. Gjernes, N. Druelle et al., "The inactivation of Arx in pancreatic $\alpha$-cells triggers their neogenesis and conversion into functional $\beta$-like cells," PLoS Genetics, vol. 9, no. 10, article e1003934, 2013. 

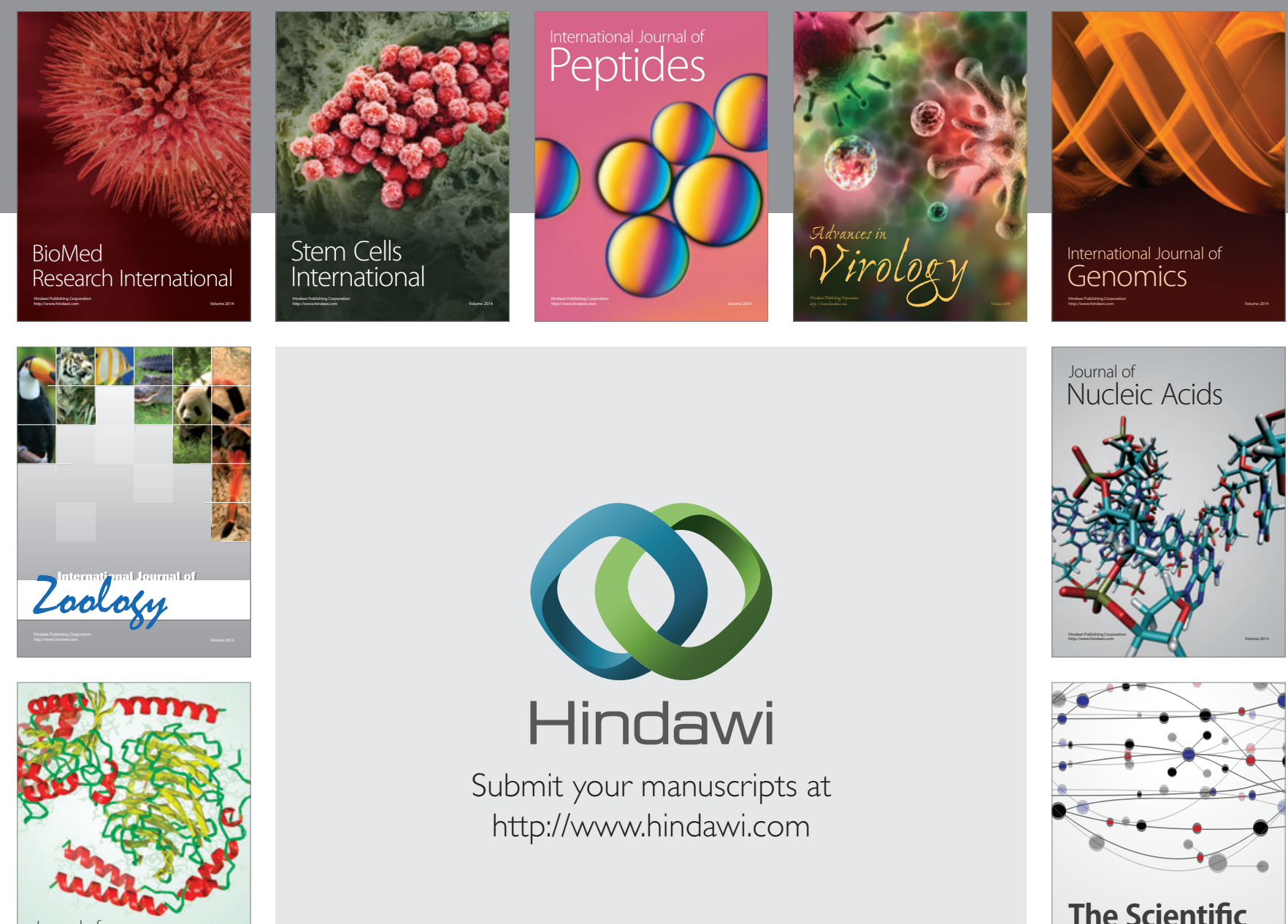

Submit your manuscripts at

http://www.hindawi.com

Journal of
Signal Transduction
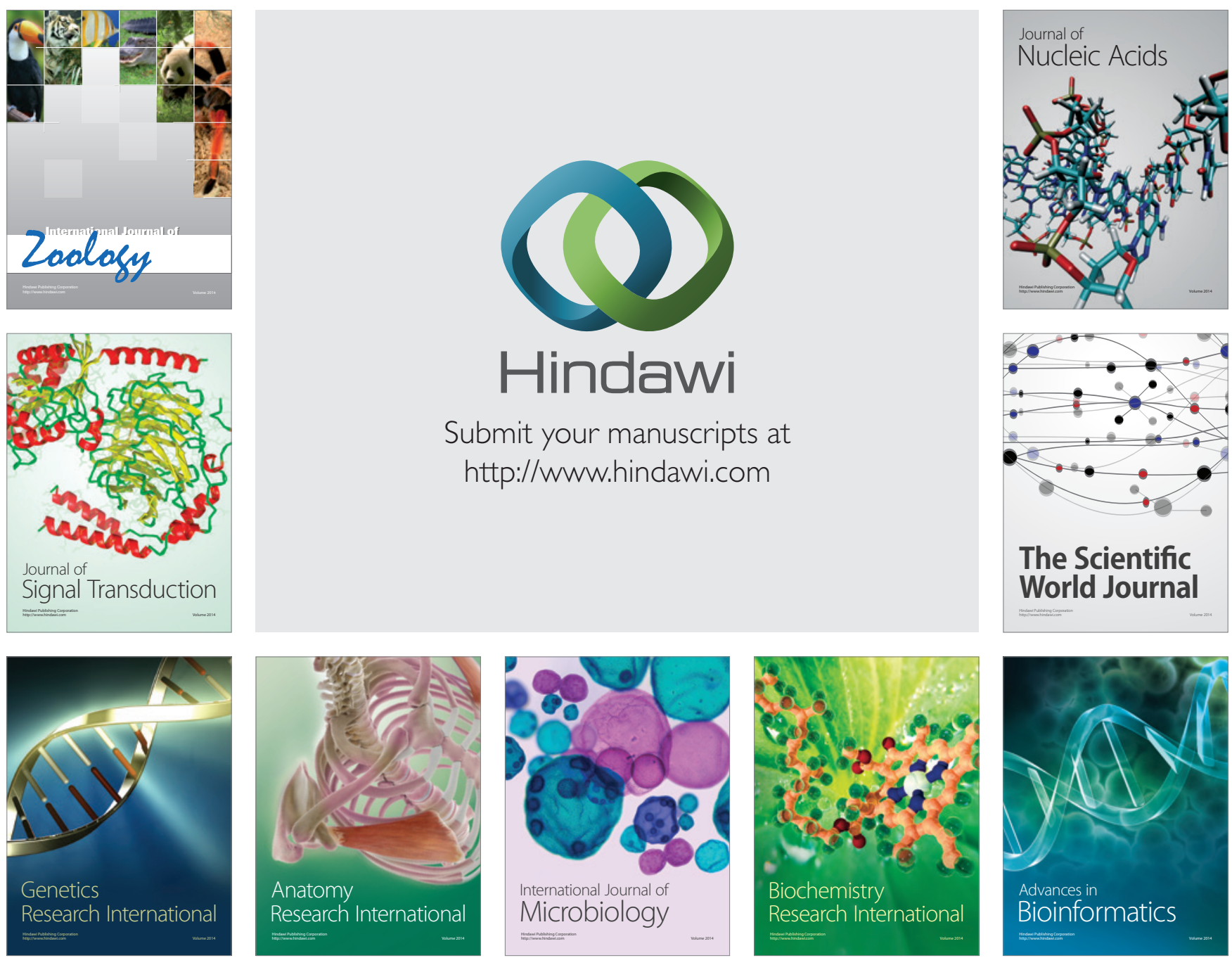

The Scientific World Journal
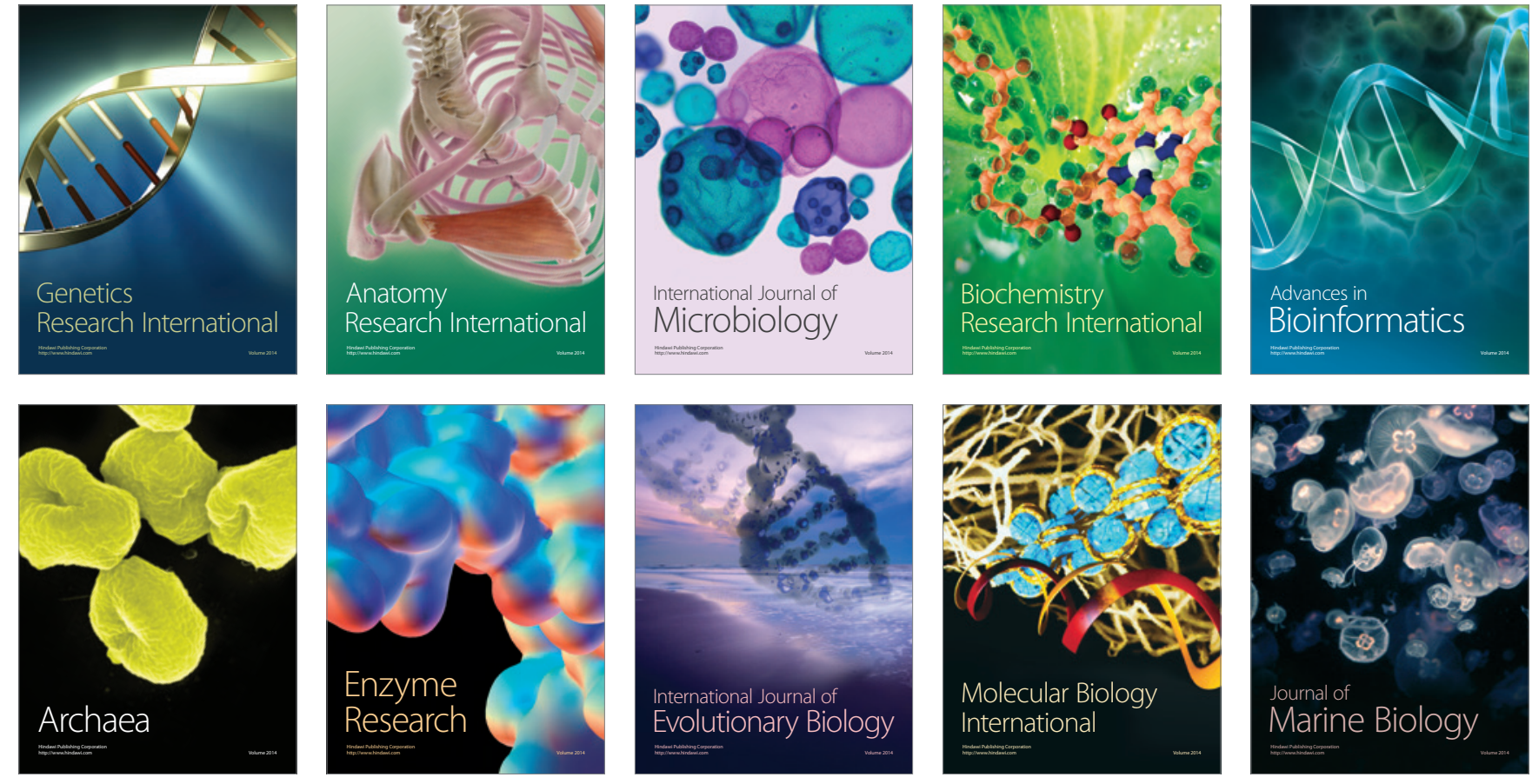